\title{
ANALISIS KARAKTERISTIK ON STREET PARKING DI RUAS JALAN BRIGJEND SLAMET RIYADI (SIMPANG EMPAT GLADAG - SIMPANG EMPAT PASAR PON) KOTA SURAKARTA
}

\author{
David Yudo Anggoro ${ }^{1}$, Budi Yulianto ${ }^{2)}$, Amirotul Mahmudah ${ }^{3)}$ \\ ${ }^{1)}$ Mahasiswa Program S1 Teknik Sipil, Universitas Sebelas Maret \\ 23)3 Pengajar Program Studi Teknik Sipil, Universitas Sebelas Maret \\ Jalan Ir. Sutami No. 36 A Surakarta 57126. Telp: (0271) 647069. Email: yudodavid@ gmail.com
}

\begin{abstract}
The increasing growth of private vehicles create a variety of problems in urban traffic, especially on Brigjend Slamet Riyadi Street (Gladag Intersection - Pasar Pon Intersection) which is a Central Business District (CBD) area in Surakarta City. Traffic engineering management efforts to reduce traffic problems by applying the contra flow system. Contra flow system is planned by the Department of Transportation Communications and Informatics (Dishubkominfo) Surakarta City from Gladag to Gendengan (Subarno, 2016). But vehicles that can contra flow on the main street is only Solo Batik. Trans bus (BST). Thus, the people from the eastern region need no more difficulty when up the BST against the current to reach the western area using public transport. To realize the contra flow system, it is necessary to analyze the characteristics of on street parking in Brigjend Slamet Riyadi Street on the north side of the street. It aims to determine the condition of parking and problems that exist, so that can be done efforts to improve parking management. Characteristics of on street parking are volume, accumulation, duration, static capacity, parking index, turn over, dynamic capacity, parking activity index (IAP), and V/C ratio. Based on the analysis of the characteristics of on street parking, the condition of parking service is still not optimal. This can be known from the parking index value and $V / C$ ratio $>1$, parking duration $>2$ hours, and the number of illegal parking. With the application of contra flow, the condition of parking characteristics decreases. This is due to the change in parking angle which originally $38^{\circ}$ to $0^{\circ}$, so the parking space is reduced. Parking management solution by limiting the parking duration up to 2 bours. Assuming employees and shopkeepers will switch to public transit BST or shuttle system.
\end{abstract}

Keywords: on street parking characteristics, contra flow, parking duration, parking turn over, parking activity index.

\begin{abstract}
Abstrak
Meningkatnya pertumbuhan kendaraan pribadi menimbulkan berbagai masalah pada lalu lintas perkotaan, khususnya pada Jalan Brigjend Slamet Riyadi (Simpang Empat Gladag - Simpang Empat Pasar Pon) yang merupakan kawasan Central Business District (CBD) di Kota Surakarta. Upaya manajemen rekayasa lalu lintas untuk mengurangi permasalahan lalu lintas yaitu dengan penerapan sistem contra flow. Sistem contra flow direncanakan oleh Dinas Perhubungan Komunikasi dan Informatika (Dishubkominfo) Kota Surakarta dari Gladag sampai Gendengan (Suharno, 2016). Namun kendaraan yang bisa contra flow di jalan utama tersebut hanya bus Batik Solo Trans (BST). Dengan demikian, maka masyarakat yang berasal dari wilayah timur tidak perlu lagi kesulitan saat naik BST yang melawan arus untuk menjangkau daerah barat menggunakan kendaraan umum. Untuk merealisasikan sistem contra flow, maka perlu dilakukan analisis karakteristik on street parking di ruas Jalan Brigjend Slamet Riyadi bagian utara jalan. Hal ini bertujuan untuk mengetahui kondisi parkir dan permasalahan yang ada, sehingga dapat dilakukan upaya perbaikan manajemen parkir. Karakteristik on street parking berupa volume, akumulasi, durasi, kapasitas statis, indeks parkir, turn over, kapasitas dinamis, indeks aktifitas parkir (IAP), dan $V / C$ ratio. Berdasarkan hasil analisis karakteristik on street parking, kondisi pelayanan parkir saat ini masih belum optimal. Hal ini dapat diketahui dari nilai indeks parkir dan $V / C$ ratio $>1$, durasi parkir $>2$ jam, dan banyaknya ilegal parkir. Dengan penerapan contra flow, kondisi karakteristik parkir menurun. Hal ini disebabkan karena perubahan sudut parkir yang awalnya $38^{\circ}$ menjadi $0^{\circ}$, sehingga ruang parkir berkurang. Solusi manajemen parkir dengan melakukan pembatasan durasi parkir maksimal 2 jam. Dengan asumsi pegawai dan pemilik toko akan beralih menggunakan angkutan umum BST ataupun sistem antar jemput.
\end{abstract}

Kata kunci: karakteristik on street parking, contra flow, durasi parkir, pergantian parkir, indeks aktifitas parkir. 


\section{PENDAHULUAN}

Unit Pelayanan Pendapatan Daerah (UPPD) atau Samsat Surakarta mendata jumlah kendaraan baru di Surakarta selama setahun bertambah 22.534 unit. Rata-rata jumlah kendaraan di Surakarta bertambah 2.000 unit setiap bulan. Ada 22.534 unit kendaraan pada Januari-November 2016 dengan didominasi sepeda motor (Ismail, M., 2017).

Meningkatnya pertumbuhan kendaraan menimbulkan berbagai masalah pada lalu lintas perkotaan, khususnya pada Jalan Brigjend Slamet Riyadi (Simpang Empat Gladag - Simpang Empat Pasar Pon) yang merupakan kawasan Central Business District (CBD) di Kota Surakarta. Upaya manajemen rekayasa lalu lintas untuk mengurangi permasalahan lalu lintas yaitu dengan penerapan sistem contra flow. Sistem contra flow direncanakan oleh Dinas Perhubungan Komunikasi dan Informatika (Dishubkominfo) Kota Surakarta dari Gladag sampai Gendengan (Suharno, 2016). Namun kendaraan yang bisa contra flow di jalan utama tersebut hanya bus Batik Solo Trans (BST). Dengan demikian, maka masyarakat yang berasal dari wilayah timur tidak perlu lagi kesulitan saat naik BST yang melawan arus untuk menjangkau daerah barat menggunakan kendaraan umum.

Untuk merealisasikan sistem contra flow, maka perlu dilakukan analisis karakteristik on street parking di ruas Jalan Brigjend Slamet Riyadi bagian utara jalan. Hal ini bertujuan untuk mengetahui kondisi parkir dan permasalahan yang ada, sehingga dapat dilakukan upaya perbaikan manajemen parkir.

Penelitian tentang masalah parkir pernah dilakukan sebelumnya oleh Arishandi dkk (2017), Chen dkk (2016), Evriyani dkk (2014), Hartono (2016), Kusumanegara dkk (2015), Martens dkk (2009), dan Wahdan dkk (2014). Secera umum penelitian ini memiliki persamaan dengan penelitian yang dilakukan sebelumnya yaitu moda yang diteliti yaitu jenis mobil penumpang dan sepeda motor, serta parameter penunjang berupa volume kendaraan dan kapasitas ruang parkir. Perbedaan penelitian ini dengan penelitian Arishandi dkk (2017) dan Evriyani dkk (2014) adalah lokasi penelitian dan metode survei. Metode survei yang digunakan dalam penelitian ini adalah survei patroli. Perbedaan penelitian Chen dkk (2016) terletak pada lokasi penelitian, model penelitian berupa cellular automation (CA), dan objek penelitian ditambah dengan sepeda. Perbedaan penelitian Hartono (2016) terletak pada sistem contra flow yang tidak mempertimbangkan karakteristik parkir existing. Perbedaan penelitian Martens dkk (2009) terletak pada lokasi penelitian dan metode survei yang berupa model pencarian parkir non-spasial dan model geosimulasi eksplisit dari proses parkir. Perbedaan penelitian Kusumanegara dkk (2015) dan Wahdan dkk (2014) terletak pada lokasi penelitian, untuk metode survei yang digunakan sama yaitu metode survei patroli. Secara garis besar hal yang membedakan penelitian ini adalah karakteristik on street parking dilakukan dengan metode survei patroli, sehingga dapat diketahui permasalahan parkir yang ada. Kemudian mempertimbangkan alternatif solusi manajemen parkir, dimana dilakukan perbaikan sistem parkir yang berhubungan dengan pelaksanaan rencana sistem contra flow untuk bus BST.

\section{DASAR TEORI}

\section{Karakteristik Parkir}

Karakteristik parkir digambarkan dalam bentuk parameter-parameter berikut ini :

\section{Rata-Rata Lamanya (Durasi) Parkir}

Lama waktu parkir atau durasi adalah lama waktu yang dihabiskan oleh pemarkir pada ruang parkir. Lamanya parkir dinyatakan dalam jam. Rumus yang digunakan untuk menghitung rata-rata lamanya parkir adalah

$D=\frac{\sum(N x) \cdot(X) \cdot(I)}{N t}$

Dimana:

$\mathrm{D}=$ Rata-rata lama parkir atau durasi (jam/kendaraan).

$\mathrm{N}_{\mathrm{x}} \quad=$ Jumlah kendaraan yang parkir selama interval waktu survei (kendaraan).

$\mathrm{X}=$ Jumlah dari interval.

I = Interval waktu survei (jam)

$\mathrm{N}_{\mathrm{t}} \quad=$ Jumlah total kendaraan selama waktu survei. 
Rata-rata lamanya durasi parkir dapat diklasifikasikan menjadi beberapa kategori yang berbeda berdasarkan lamanya waktu, sesuai dengan Tabel 1.

Tabel 1. Kategori Durasi Parkir Berdasarkan Lamanya Waktu

\begin{tabular}{cl}
\hline Kategori & \multicolumn{1}{c}{ Keterangan } \\
\hline 1 & Durasi parkir pendek, pada umumnya kendaraan parkir kurang dari setengah jam \\
\hline 2 & Durasi parkir menengah, pada umumnya kendaraan parkir selama 2-4 jam \\
\hline 3 & Durasi parkir panjang, pada umumnya kendaraan parkir selama 12-16 jam \\
\hline 4 & Durasi parkir lebih dari satu malam
\end{tabular}

Sumber: Evriyani, D., Nahry, dan Soehodho, S., 2014

\section{Pergantian Parkir (Parking Turnover)}

Pergantian parkir atau Parking Turnover menunjukkan tingkat penggunaan ruang parkir yang diperoleh dengan membagi volume parkir dengan jumlah ruang parkir untuk periode waktu tertentu. Rumus yang digunakan untuk menyatakan pergantian parkir adalah sebagai berikut:

$\mathrm{TR}=\frac{N t}{S \cdot T s}$.

Dimana:

$\mathrm{TR}=$ Angka pergantian parkir (kend/SRP/jam)

$\mathrm{Nt}=$ Jumlah total kendaraan selama waktu survei (kendaraan)

$\mathrm{S} \quad=$ Jumlah petak parkir yang tersedia di lokasi studi

Ts = Lama periode analisis/waktu survei (jam)

Tingkat pergantian parkir juga dapat diklasifikasikan menjadi beberapa kategori yang berbeda berdasarkan lamanya waktu dan frekuensi penggunaannya, sesuai dengan Tabel 2.

Tabel 2. Kategori Parking Turnover Berdasarkan Lamanya Waktu

\begin{tabular}{ll}
\hline \multicolumn{1}{c}{ Kategori parking turnover } & \multicolumn{1}{c}{ Contoh Tipe Pengguna } \\
\hline Low turnover & Durasi parkir sepanjang hari \\
\hline Medium turnover & $\begin{array}{l}\text { Durasi parkir antara 2-12 jam, pada umumnya untuk parkir apartemen } \\
\text { dan hotel }\end{array}$ \\
\hline High turnover & $\begin{array}{l}\text { Durasi parkir pendek, pada umumnya untuk parkir di pusat } \\
\text { perbelanjaan }\end{array}$ \\
\hline
\end{tabular}

Sumber: Evriyani, D., Nahry, dan Soehodho, S., 2014

\section{METODE PENELITIAN}

\section{Pengumpulan Data}

Pengumpulan data pada penelitian ini terbagi atas pengumpulan data primer dan data sekunder. Data sekunder didapat dari data yang sudah tersedia, ataupun wawancara dengan pihak terkait berupa denah lokasi parkir dan informasi lain. Data primer diperoleh melalui survei patroli. Data primer yang dibutuhkan antara lain desain survei, waktu masuk dan keluar kendaraan dari lokasi parkir, jenis dan plat nompr kendaraan, dan ukuran karakteristik parkir dimensional.

\section{Waktu Penelitian}

Penelitian ini telah dilaksanakan pada hari Rabu tanggal 17 Mei 2017 untuk Simpang Empat Nonongan Simpang Empat Pasar Pon dan hari Senin tanggal 22 Mei 2017 untuk Simpang Empat Gladag - Simpang Empat Nonongan. Penelitian dilaksanakan pada jam 13.00 - 18.00 WIB. 


\section{Lokasi Penelitian}

Lokasi dilakukannya penelitian ini adalah Jalan Brigjend Slamet Riyadi yang terletak di Kota Surakarta. Lokasi penelitian dibagi menjadi 2 ruas jalan yaitu Simpang Empat Gladag - Simpang Empat Nonongan dan Simpang Empat Nonongan - Simpang Empat Pasar Pon.

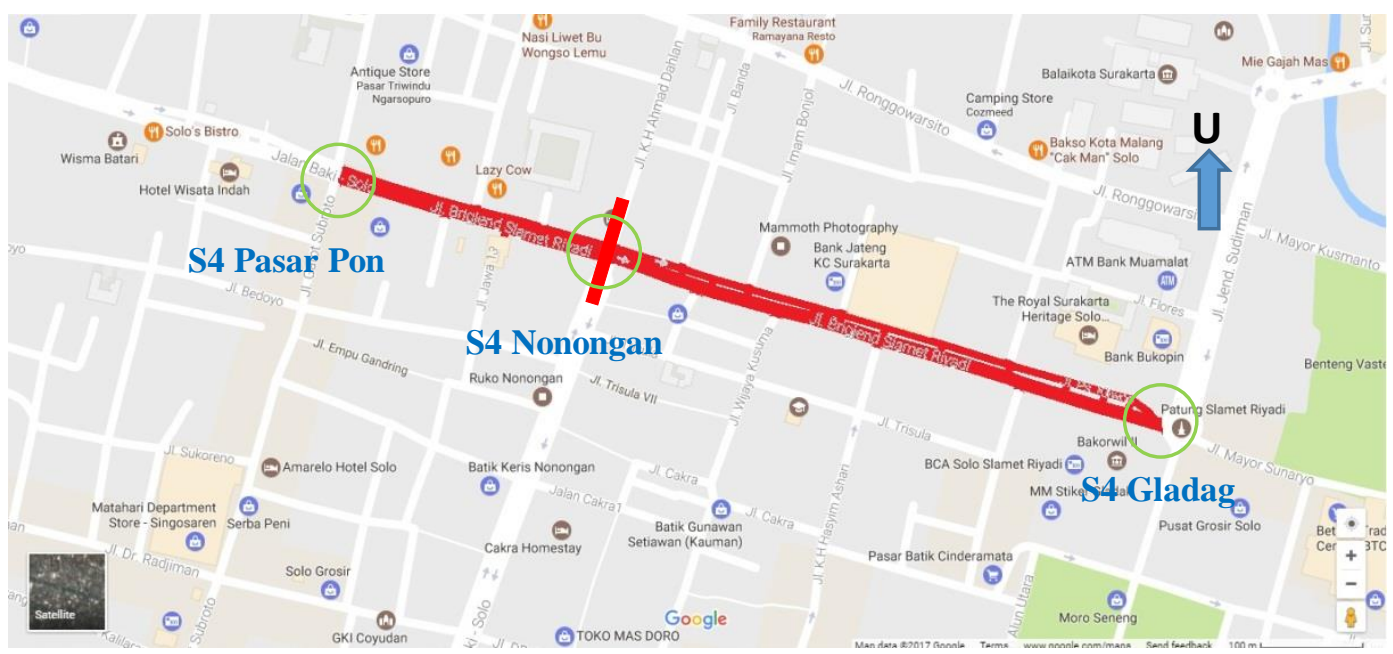

Gambar 1. Lokasi Penelitian

\section{Diagram Alir Penelitian}

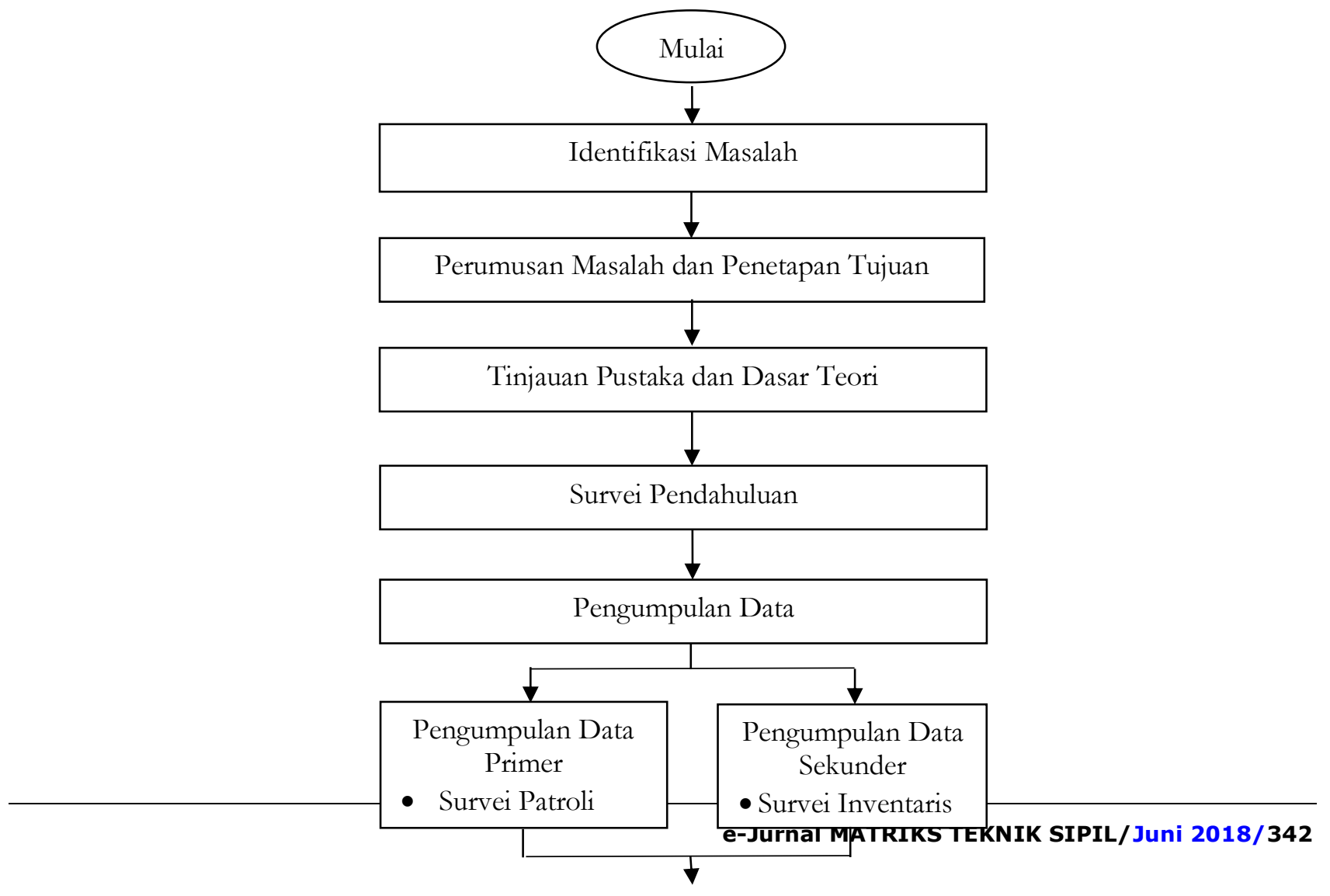


Lanjutan

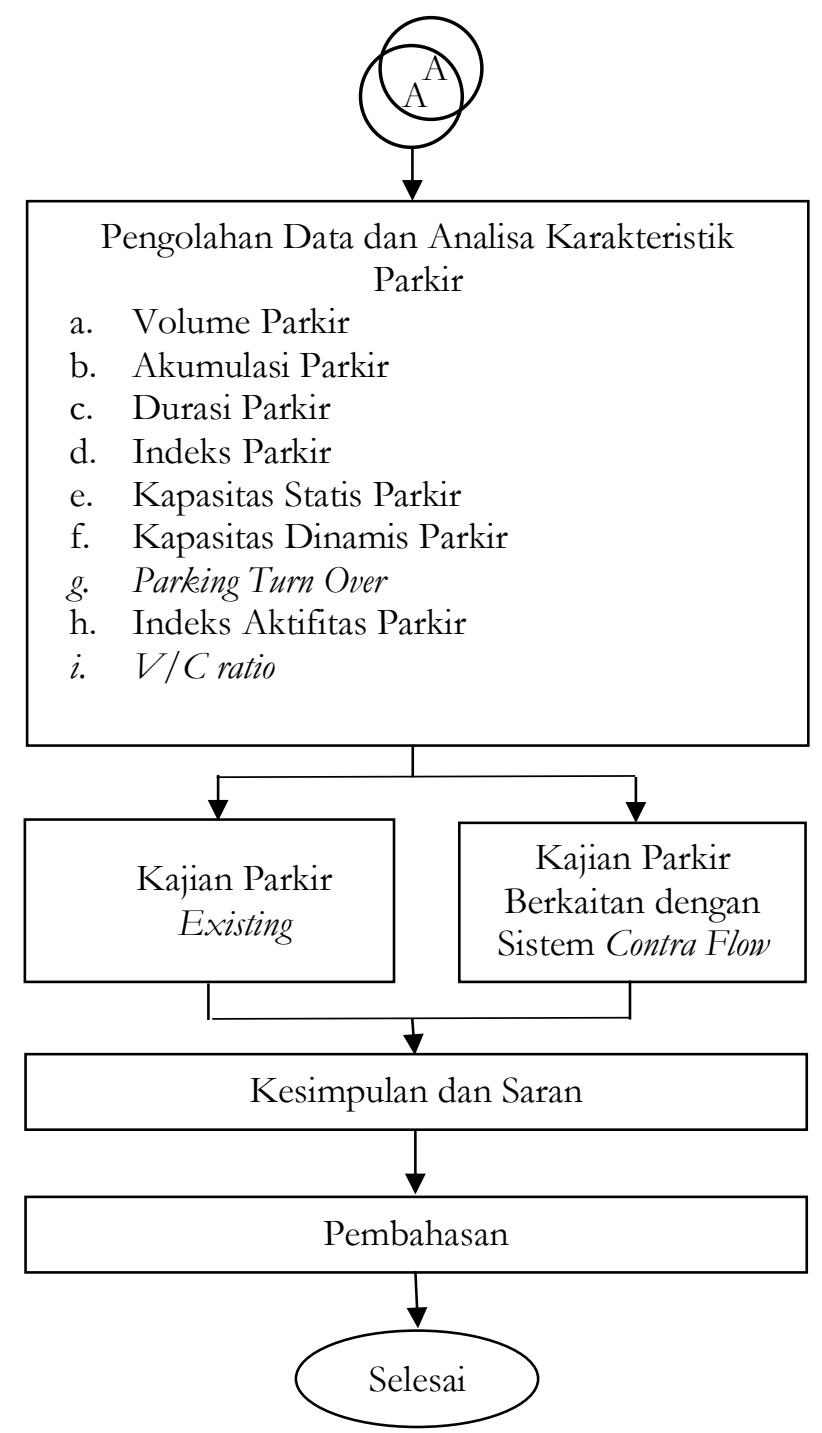

Gambar 2. Diagram Alir Penelitian

\section{ANALISIS DATA DAN PEMBAHASAN}

\section{Karakteristik Parkir}

Pada saat surveyor melakukan survei patroli, didapati mobil penumpang dan mobil barang menempati lokasi parkir yang sama. Oleh karena itu, dalam penelitian ini mobil penumpang dan mobil barang dianggap sebagai kendaraan mobil.

Analisis data karakteristik parkir dilakukan setiap segmen dan setiap ruas jalan. Meliputi data kendaraan sepeda motor dan kendaraan mobil yang parkir di dalam marka parkir (legal), maupun di luar marka parkir (ilegal). Marka parkir membentuk sudut $38^{\circ}$.

Jumlah volume kendaraan dapat dilihat pada Tabel 3 dan Tabel 4, seperti berikut :

Tabel 3. Volume Parkir Ruas Jalan Simpang Empat Gladag - Simpang Empat Nonongan (Kendaraan)

\section{Ruang Parkir} Jumlah Sepeda Motor

Jumlah Mobil 


\begin{tabular}{cccc}
\hline Legal & 22 & 104 & 104 \\
\hline Ilegal & 60 & 208 & \\
\hline Total & 82 & 204 \\
\hline
\end{tabular}

Sumber: Hasil Analisis

Tabel 4. Volume Parkir Ruas Jalan Simpang Empat Nonongan - Simpang Empat Pasar Pon (Kendaraan)

\section{Ruang Parkir}

\begin{tabular}{ccc}
\hline Legal & 39 & 60 \\
\hline Ilegal & 39 & 99 \\
\hline Total & 78 & 159 \\
\hline
\end{tabular}

Sumber: Hasil Analisis

Akumulasi parkir kendaraan dapat dilihat pada Gambar 3, 4, 5, dan 6 seperti berikut ini :

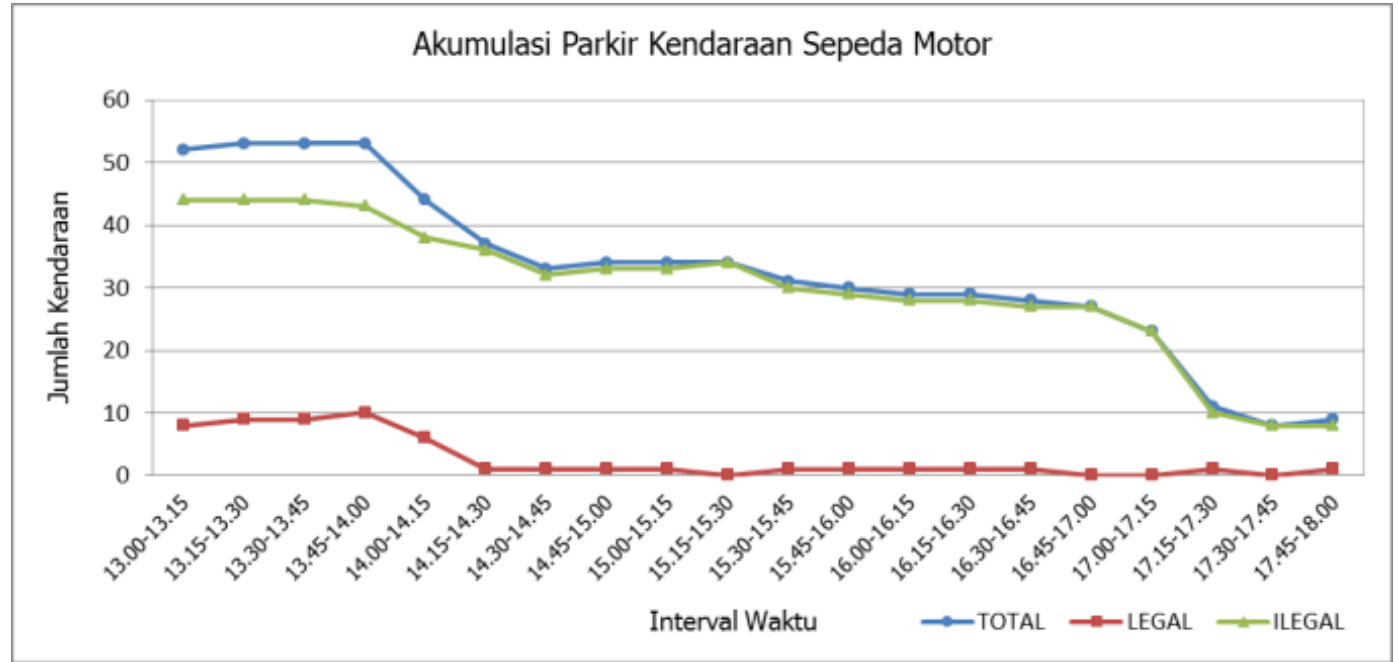

Sumber: Hasil Analisis

Gambar 3. Grafik Akumulasi Parkir Kendaraan Sepeda Motor Ruas Jalan Simpang Empat Gladag - Simpang Empat Nonongan

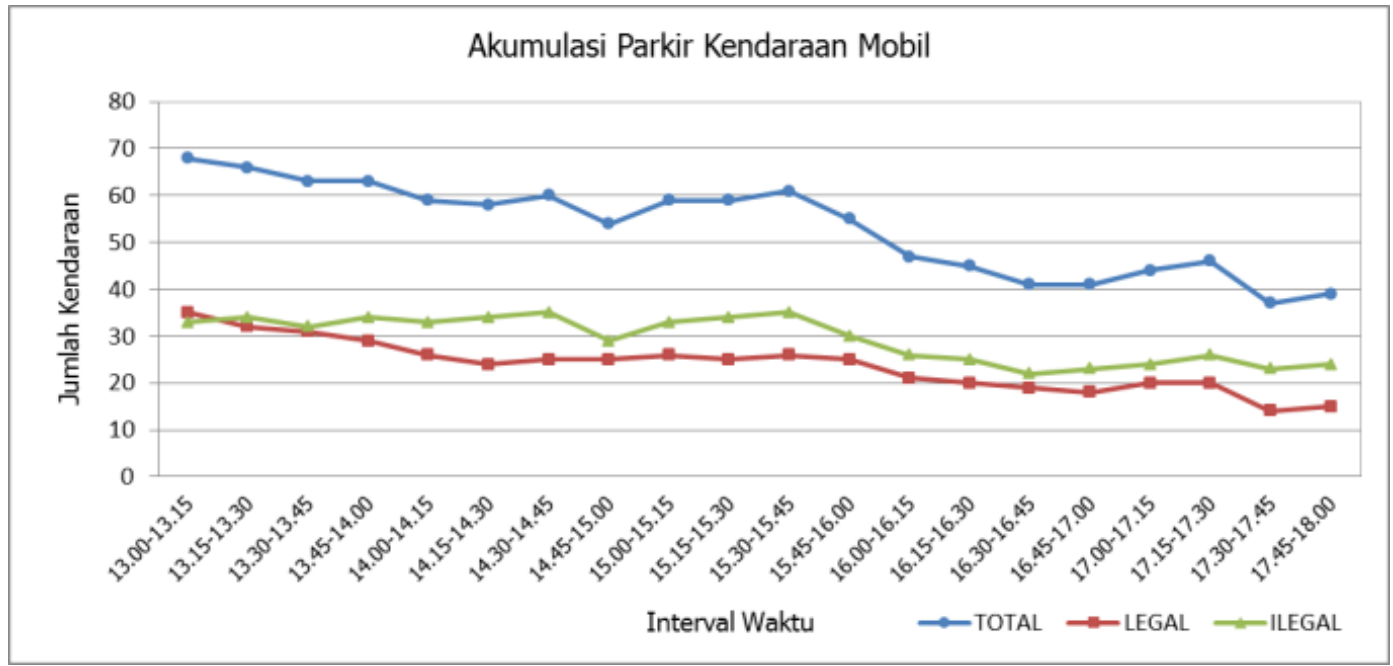

Sumber: Hasil Analisis 
Gambar 4. Grafik Akumulasi Parkir Kendaraan Mobil Ruas Jalan Simpang Empat Gladag - Simpang Empat Nonongan

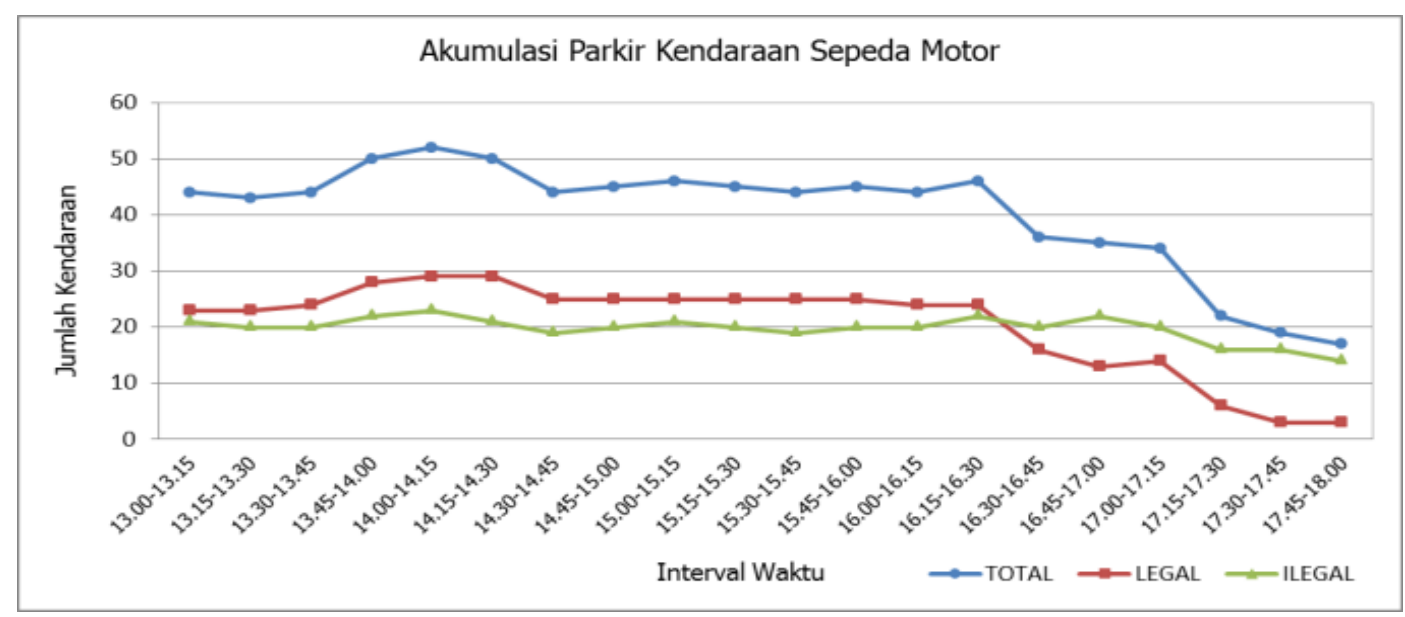

Sumber: Hasil Analisis

Gambar 5. Grafik Akumulasi Parkir Kendaraan Sepeda Motor Ruas Jalan Simpang Empat Nonongan Simpang Empat Pasar Pon

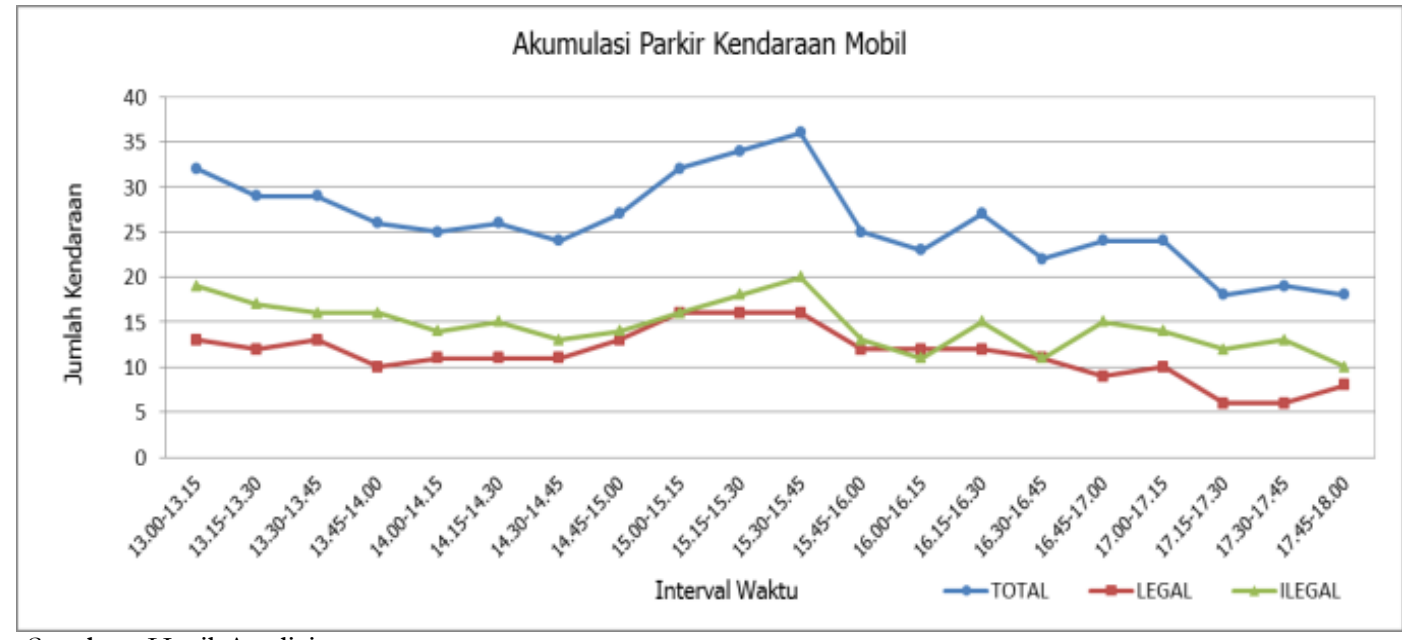

Sumber: Hasil Analisis

Gambar 6. Grafik Akumulasi Parkir Kendaraan Mobil Ruas Jalan Simpang Empat Nonongan - Simpang Empat Pasar Pon

Durasi parkir kendaraan dapat dilihat pada Tabel 5 dan Tabel 6, seperti berikut :

Tabel 5. Durasi Parkir Ruas Jalan Simpang Empat Gladag - Simpang Empat Nonongan (Jam/Kendaraan)

\begin{tabular}{ccc}
\hline Ruang Parkir & Sepeda Motor & Mobil \\
\hline Legal & 0,59 & 1,14 \\
\hline Ilegal & 2,50 & 1,14 \\
\hline Legal dan Ilegal & 1,98 & 1,28 \\
\hline
\end{tabular}

Sumber: Hasil Analisis

Tabel 6. Durasi Parkir Ruas Jalan Simpang Empat Nonongan - Simpang Empat Pasar Pon (Jam/Kendaraan) 


\begin{tabular}{ccc}
\hline Ruang Parkir & Sepeda Motor & Mobil \\
\hline Legal & 2,62 & 0,95 \\
\hline Ilegal & 2,54 & 0,74 \\
\hline Legal dan Ilegal & 2,58 & 0,82 \\
\hline
\end{tabular}

Sumber: Hasil Analisis

Untuk selengkapnya rangkuman karakteristik parkir dapat dilihat pada Tabel 7 dan Tabel 8.

Tabel 7. Rangkuman Karakteristik Parkir Ruas Jalan Simpang Empat Gladag - Simpang Empat Nonongan

\begin{tabular}{lcc}
\hline \multirow{2}{*}{ Parameter } & Sepeda Motor & Mobil \\
\cline { 2 - 3 } & Existing & Existing \\
\hline Kapasitas Statis & 52 & 62 \\
\hline Indeks Parkir & 0,63 & 0,86 \\
\hline Pergantian Parkir & 0,32 & 0,67 \\
\hline Kapasitas Dinamis & 131,00 & 242,86 \\
\hline IAP & 0,10 & 0,45 \\
\hline V/C ratio & 0,63 & 0,86 \\
\hline
\end{tabular}

Sumber: Hasil Analisis

Tabel 8. Rangkuman Karakteristik Parkir Ruas Jalan Simpang Empat Nonongan - Simpang Empat Pasar Pon

\begin{tabular}{lcc}
\hline \multirow{2}{*}{ Parameter } & Sepeda Motor & Mobil \\
\cline { 2 - 3 } & Existing & Existing \\
\hline Kapasitas Statis & 74 & 34 \\
\hline Indeks Parkir & 0,54 & 0,76 \\
\hline Pergantian Parkir & 0,21 & 0,94 \\
\hline Kapasitas Dinamis & 143,40 & 207,92 \\
\hline IAP & 0,04 & 0,87 \\
\hline V/C ratio & 0,54 & 0,76 \\
\hline
\end{tabular}

Sumber: Hasil Analisis

\section{Usulan Perbaikan Manajemen Parkir}

Berdasarkan analisis karakteristik parkir sebelumnya, kondisi pelayanan parkir saat ini masih belum berjalan dengan baik. Hal ini dapat diketahui dari nilai indeks parkir dan $V / C$ ratio yang tinggi. Dari gambar grafik didapatkan hasil bahwa kapasitas statis legal tidak cukup menampung kebutuhan parkir, sehingga terjadi parkir ilegal. Dan hal lain yang menyebabkan pelayanan parkir belum optimal adalah dengan ditemukan banyaknya pusat bisnis yang tidak menyediakan lahan parkir untuk pegawainya, sehingga pegawai parkir di badan jalan dengan durasi parkir yang lama. Untuk meminimalisasi permasalahan parkir tersebut, maka alternatif solusi perbaikan sistem on street parking di ruas Jalan Brigjend Slamet Riyadi (Simpang Empat Gladag - Simpang Empat Pasar Pon) yaitu dengan cara pembatasan durasi parkir. Kendaraan boleh parkir maksimal selama 2 jam. Penetapan waktu 2 jam berdasarkan tabel kategori lokasi pusat perbelanjaan (Evriyani, D., Nahry, dan Soehodho, S., 2014). Apabila kendaraan melebihi durasi parkir yang diberlakukan maka akan dikenakan sanksi denda. Dengan diberlakukannya pembatasan durasi parkir maka pegawai akan kesulitan menemukan area parkir. Alternatif solusi agar mobilitas pegawai dapat terlayani adalah dengan cara kebijakan contra flow. Sistem contra flow di jalan utama tersebut disediakan untuk bus Batik Solo Trans (BST). Kebijakan contra flow akan berimbas pada berkurangnya ruang jalan karena dipakai untuk jalur bus BST. Untuk mengantisipasi hal tersebut, maka perlu dilakukan perubahan sudut parkir kendaraan mobil yang awalnya $38^{\circ}$ menjadi $0^{\circ}$. Sedangkan untuk sepeda motor sudut parkirnya tetap 90 , namun kapasitas statis parkirnya berubah dari 2 baris menjadi 1 baris. Dengan adanya perubahan nilai karakteristik parkir yang awalnya bersudut $38^{\circ}$ menjadi $0^{\circ}$, maka akan terjadi pengurangan nilai kapasitas statis parkir. Rangkuman nilai karakteristik parkir dengan sudut $38^{\circ}$ dan $0^{\circ}$ ditunjukkan pada Tabel 9 dan Tabel 10. 
Tabel 9. Rangkuman Karakteristik Parkir Ruas Jalan Simpang Empat Gladag - Simpang Empat Nonongan

\begin{tabular}{lcccccc}
\hline \multirow{2}{*}{ Parameter } & \multicolumn{3}{c}{ Sepeda Motor } & \multicolumn{3}{c}{ Mobil } \\
\cline { 2 - 7 } & 2 Baris & 1 Baris & Perubahan $(\%)$ & Sudut $38^{\circ}$ & Sudut $0^{\circ}$ & Perubahan $(\%)$ \\
\hline Kapasitas Statis & 52 & 28 & $-46,15$ & 62 & 52 & $-16,13$ \\
\hline Indeks Parkir & 0,63 & 1,16 & 85,031 & 0,86 & 1,02 & 18,761 \\
\hline Pergantian Parkir & 0,32 & 0,59 & 87,073 & 0,67 & 0,80 & 19,231 \\
\hline Kapasitas Dinamis & 131,00 & 70,54 & $-46,15$ & 242,86 & 203,69 & $-16,13$ \\
\hline IAP & 0,10 & 0,34 & 241,3 & 0,45 & 0,64 & 41,759 \\
\hline V/C ratio & 0,63 & 1,16 & 85,315 & 0,86 & 1,02 & 19,096 \\
\hline
\end{tabular}

Sumber: Hasil Analisis

Tabel 10. Rangkuman Karakteristik Parkir Ruas Jalan Simpang Empat Nonongan - Simpang Empat Pasar Pon

\begin{tabular}{lcccccc}
\hline \multirow{2}{*}{ Parameter } & \multicolumn{3}{c}{ Sepeda Motor } & \multicolumn{3}{c}{ Mobil } \\
\cline { 2 - 8 } & 2 Baris & 1 Baris & Perubahan $(\%)$ & Sudut 38 & Sudut $0^{\circ}$ & Perubahan $(\%)$ \\
\hline Kapasitas Statis & 74 & 42 & $-43,24$ & 34 & 25 & $-26,47$ \\
\hline Indeks Parkir & 0,54 & 0,96 & 76,50 & 0,76 & 1,04 & 36,00 \\
\hline Pergantian Parkir & 0,21 & 0,37 & 75,51 & 0,94 & 1,27 & 35,79 \\
\hline Kapasitas Dinamis & 143,40 & 81,39 & $-43,24$ & 207,92 & 152,88 & $-26,47$ \\
\hline IAP & 0,04 & 0,14 & 215,02 & 0,87 & 1,62 & 85,19 \\
\hline V/C ratio & 0,54 & 0,96 & 76,50 & 0,76 & 1,04 & 36,00 \\
\hline Sunyyyyyyyyyyyy
\end{tabular}

Sumber: Hasil Analisis

Dari tabel 9 dan tabel 10 terdapat peningkatan nilai indeks parkir, pergantian parkir, IAP, dan V/C ratio yang cukup besar hal ini dapat diartikan ruang parkir yang disediakan belum bisa mencukupi kebutuhan parkir kendaraan. Apabila pemberlakuan batas durasi parkir 2 jam diterapkan, diasumsikan pengguna parkir lebih dari 2 jam yaitu pegawai dan pemilik toko akan beralih menggunakan angkutan umum BST ataupun sistem antar jemput. Dengan asumsi tersebut, maka rangkuman nilai karakteristik parkir dapat dilihat pada tabel 11 dan 12 sebagai berikut:

Tabel 11. Rangkuman Karakteristik Parkir Ruas Jalan Simpang Empat Gladag - Simpang Empat Nonongan

\begin{tabular}{lcccccc}
\hline \multirow{2}{*}{ Parameter } & \multicolumn{3}{c}{ Sepeda Motor } & \multicolumn{3}{c}{ Mobil } \\
\cline { 2 - 8 } & 2 Baris & 1 Baris & Perubahan $(\%)$ & Sudut 38 & Sudut $0^{\circ}$ & Perubahan $(\%)$ \\
\hline Volume & 82 & 57 & $-30,49$ & 208 & 181 & $-12,98$ \\
\hline Kapasitas Statis & 52 & 28 & $-46,15$ & 62 & 52 & $-16,13$ \\
\hline Indeks Parkir & 0,63 & 0,40 & $-36,20$ & 0,86 & 0,55 & $-35,96$ \\
\hline Pergantian Parkir & 0,32 & 0,41 & 30,00 & 0,67 & 0,70 & 4,33 \\
\hline Kapasitas Dinamis & 131,00 & 142,5 & 8,78 & 242,86 & 332,58 & 36,94 \\
\hline IAP & 0,10 & 0,17 & 70,65 & 0,45 & 0,49 & 8,53 \\
\hline V/C ratio & 0,63 & 0,40 & $-36,10$ & 0,86 & 0,54 & $-36,95$ \\
\hline Sumber & & & & & &
\end{tabular}

Sumber: Hasil Analisis

Tabel 12. Rangkuman Karakteristik Parkir Ruas Jalan Simpang Empat Nonongan - Simpang Empat Pasar Pon

\begin{tabular}{|c|c|c|c|c|c|c|}
\hline \multirow{2}{*}{ Parameter } & \multicolumn{3}{|c|}{ Sepeda Motor } & \multicolumn{3}{|c|}{ Mobil } \\
\hline & 2 Baris & 1 Baris & Perubahan $(\%)$ & Sudut $38^{\circ}$ & Sudut $0^{\circ}$ & Perubahan $(\%)$ \\
\hline
\end{tabular}




\begin{tabular}{lcccccc}
\hline Volume & 78 & 40 & $-48,72$ & 159 & 148 & $-6,92$ \\
\hline Kapasitas Statis & 74 & 42 & $-43,24$ & 34 & 25 & $-26,47$ \\
\hline Indeks Parkir & 0,54 & 0,20 & $-63,23$ & 0,76 & 0,64 & $-16,31$ \\
\hline Pergantian Parkir & 0,21 & 0,19 & $-9,87$ & 0,94 & 1,18 & 26,16 \\
\hline Kapasitas Dinamis & 143,40 & 201,2 & 40,30 & 207,92 & 229,81 & 10,53 \\
\hline IAP & 0,04 & 0,04 & $-9,99$ & 0,87 & 1,40 & 60,04 \\
\hline V/C ratio & 0,54 & 0,20 & $-63,23$ & 0,76 & 0,64 & $-16,31$ \\
\hline
\end{tabular}

Sumber: Hasil Analisis

Dari Tabel 11 dan 12 dapat diketahui bahwa ruang parkir yang disediakan masih mencukupi kebutuhan parkir. Dari hasil analisis IAP di Ruas Jalan 2, menunjukkan intensitas pergantian parkir kendaraan mobil relatif tinggi.

\section{SIMPULAN}

Dari penelitian ini dapat ditarik kesimpulan sebagai berikut:

1. Berdasarkan hasil analisis karakteristik parkir, kondisi pelayanan parkir saat ini masih belum berjalan dengan baik. Hal ini dapat diketahui dari:

- Nilai indeks parkir dan $V / C$ ratio $>1$.

- Durasi parkir $>2$ jam.

- Banyak ilegal parkir.

2. Dengan penerapan contra flow, kondisi karakteristik parkir menurun. Hal ini disebabkan karena perubahan sudut parkir yang awalnya $38^{\circ}$ menjadi $0^{\circ}$, sehingga ruang parkir berkurang. Solusi manajemen parkir dengan melakukan pembatasan durasi parkir maksimal 2 jam. Dengan asumsi pegawai dan pemilik toko akan beralih menggunakan angkutan umum BST ataupun sistem antar jemput.

\section{SARAN}

Saran-saran yang dapat diberikan pada kajian ini adalah sebagai berikut:

1. Perlu kajian lebih lanjut untuk menentukan denda apa yang dapat memberikan efek jera agar kendaraan tidak diparkir melebihi durasi yang ditentukan.

2. Untuk menerapkan pembatasan durasi parkir diperlukan sistem parkir yang baik. Untuk menentukan sistem parkir yang baik maka perlu dilakukan kajian mengenai sistem parkir, baik yang dilakukan secara manual maupun elektronik. 


\section{DAFTAR PUSTAKA}

Abubakar, I, dkk. 1998. Pedoman Perencanaan dan Pengoperasian Fasilitas Parkir. Jakarta : Direktorat Bina Sistem Lalu Lintas dan Angkutan Kota Direktorat Jenderal Perhubungan Darat.

Arishandi, N.G., Suthanaya, P.A., dan Wedagama, D.M.P., 2017. Analisis Karakteristik dan Kebutuhan Parkir Terminal Kargo di Kota Denpasar. Universitas Udayana : Jurnal Spektran. Vol. 5, No.1 : 1-87.

Chen, J., dkk. 2016. Simulating the Impacts of on-Street Vehicle Parking on Traffic Operations on Urban Streets Using Cellular Automation. Southeast University. China

Direktorat Jenderal Pajak, 2009. Undang-Undang Republik Indonesia Nomor 28 Tahun 2009 tentang Pajak Daerah dan Retribusi Daerah.

Direktorat Jenderal Perhubungan Darat, 1993. Undang-Undang Republik Indonesia Nomor 14 Tahun 1992 tentang Lalu Lintas dan Angkutan Jalan beserta Peraturan Pelaksanaannya.

Evriyani, D., Nahry, dan Soehodho, S., 2014. Kajian Analisis Karakteristik Parkir Off-Street Kendaraan Angkutan Barang dan Pengantaran Barang di Pusat Perbelanjaan Pasar Jatinegara. The 17th FSTPT International Symposium. Universitas Jember. Jember.

Gustaman, Y., 2017. Lalu Lintas Jalan Slamet Riyadi Solo Diusulkan Jadi Dua Arah. Diambil dari: http://www.tribunnews.com/regional/2015/02/25/ lalu-lintas-jalan-slamet-riyadi-solo-diusulkan-jadidua-arah

Hobbs, F.D., 1995. Perencanaan dan Teknik Lalu Lintas Edisi Kedua. Yogyakarta: Gadjah Mada University Press.

Hartono, Dedy Hartono., dkk. 2016. Kajian Sistem Contra Flow Bus Lanes di Jalan Brigjend Slamet Riyadi Surakarta. Universitas Sebelas Maret.

Ismail, M., 2017. Setahun, Ada Tambahan 22.534 Unit Kendaraan Baru di Solo. Diambil dari: http://www.solopos.com/2017/01/05/transportasi-solo-setahun-kendaraan-baru-bertambah-22-534$\underline{\text { unit-781784 }}$

Kementrian PPN/Bappenas. 2015. Toolkit untuk Mobilitas Perkotaan di Indonesia Manajemen Parkir di Perkotaan. Jakarta.

Kusumanegara, D., dkk. 2015. Komparasi Parkir On Street terhadap Kinerja Jalan dengan Median dan Jalan tanpa Median Menggunakan Metode Simulasi (Studi Kasus Jalan K.H Agus Salim dan Jalan Pandanaran). Universitas Diponegoro : Jurnal Karya Teknik Sipil. Vol. 4, No. 1 : 145-154.

Martens, K. dkk. 2005. The Dilemma of On-street Parking Policy: Exploring Cruising for Parking Usin an Agent-based Model. Radboud University Nijmegen.

Menteri Perhubungan Republik Indonesia, 1993. Keputusan Menteri Perhubungan Nomor : KM 66 Tahun 1993 tentang Fasilitas Parkir untuk Umum.

Pemerintah Republik Indonesia. 2009. Undang-Undang No. 22 Tahun 2009 Tentang Lalu Lintas dan Angkutan Jalan.

Suharno, 2017. Jalur Contra Flow BST Slamet Riyadi Solo Kembali Tertunda. Diambil dari: http://jateng.tribunnews.com/2017/02/27/jalur-contra-flow-bst-slamet-riyadi-solo-kembali-ditunda?

Wahdan, Yaumil, dkk. 2014. Analisis Karakteristik Parkir pada Badan Jalan dan Dampaknya Terhadap Lalu Lintas (Studi Kasus: Jalan Siliwangi Kabupaten Garut). Sekolah Tinggi Teknologi Garut. Garut. 